\title{
A aprendizagem escolar e a formação de professores na perspectiva da psicologia histórico-cultural e da teoria da atividade
}

\section{The learning process in the school and the formation of teachers in the perspective of the historic-cultural psycology and the activity theory}

\author{
José Carlos Libâneo*
}

\begin{abstract}
RESUMO
Este trabalho avalia possibilidades teóricas de renovação das práticas de formação inicial e continuada de professores com base na concepção histórico-cultural da aprendizagem escolar, compreendendo o trabalho de professor efetivamente como atividade teórica e prática. Após constatação das demandas formativas postas ao desenvolvimento teórico da didática em face das exigências educacionais contemporâneas, são apontados elementos teóricos da concepção histórico-cultural e suas vertentes, com destaque à atividade de aprendizagem escolar. No final, são apresentadas as possibilidades de aplicação dessa teoria à formação de professores, numa tentativa de buscar um paradigma teoricamente mais ampliado de orientação das práticas de formação profissional de professores.

Palavras-chave: Teoria histórico-cultural da atividade, ensino desenvolvimental, formação de professores, pensamento de V. Davydov.
\end{abstract}

\footnotetext{
ABSTRACT

This work appraises theoretical possibilities of renovation in the practices of formation of teachers. Acknowledging the importance of reflexivity

* Professor da Pontifícia Universidade Católica de Goiás. E-mail: jclibaneo@uol.com.br
} 
and refusing the idea of the professional practice as a merely technical activity, the work of the teacher is understood as a practical and theoretical activity, according to a historic e social conception and the theory of the activity. Initially, there is a brief exposition on the current debate about the contemporary educational demands. After that, theoretical elements of the historic-cultural conception and its variations are presented, pointing out the learning activity. Finally, the possible applications of this theory in the formation of teachers is considered as an alternative to the current formation models. The author expects this work to be evaluated as a first approach to the theme, within the limits of his intellectual experience, in the search for a theoretically wider paradigm to guide the practice of formation of teachers.

Key-words: Historic cultural theory of activity, developmental teaching, formation of teachers, V. Dadidov's thinking.

\section{As atuais demandas formativas}

Os sistemas de ensino e as escolas encontram-se, presentemente, frente a novas demandas formativas. Estudos recentes sobre os processos do pensar e do aprender, para além da acentuação do papel ativo dos sujeitos na aprendizagem, insistem na necessidade de os sujeitos desenvolverem habilidades de pensamento, competências cognitivas. Para CASTELls (In HARGREAVES, 2001), a tarefa das escolas e dos processos educativos é desenvolver no sujeito que aprende a capacidade de aprender, em razão das exigências postas pelo volume crescente de dados acessíveis na sociedade e das redes informacionais, da necessidade de tratar com um mundo diferente e, também, de educar a juventude em valores e ajudá-la a construir personalidades flexíveis e eticamente ancoradas. Também MORIN expressa a exigência de se desenvolver uma inteligência geral que saiba discernir o contexto, o global, o multidimensional, a interação complexa dos elementos. Conforme esse autor, "a compreensão dos dados particulares necessita da ativação da inteligência geral, que opera e organiza a mobilização dos conhecimentos de conjunto em cada caso particular" (2000, p. 39). Outras pesquisas vêm mostrando o impacto dos meios de comunicação na configuração dos modos de pensar e das práticas sociais da juventude (por ex., BARBERO, 2003; PORTO, 2003; BELLONI, 2002), das tecnologias e dos meios informacionais, dos crescentes processos de homogeneização e diversificação cultural, afetando os processos de ensino e aprendizagem. 
Em anos recentes, ganharam destaque no Brasil os estudos sobre a formação de professores em paralelo à tendência mundial das investigações em torno desse tema, destacando-se na preferência dos pesquisadores a denominada "concepção do professor reflexivo". A abordagem reflexiva na formação de professores aparece no final dos anos 1970 e início dos anos 1980, geralmente associada às reformas educativas implementadas em vários países europeus e latino-americanos, tendo ganhado visibilidade sem precedentes na pesquisa educacional brasileira. Todavia, outras abordagens do tema se fazem presente no campo investigativo da educação, associadas a concepções de ensino e aprendizagem. (PIMENTA, 2002; LIBÂNEO, 2002).

A didática atual tem se nutrido dessas investigações em busca de novos aportes teóricos para atender a necessidades educativas presentes, especialmente as relacionadas com a formação de professores, considerando-se que a escola básica continua sendo um dos lugares de mediação cultural para a escolarização. As mudanças nas formas de aprender afetam as formas de ensinar, em vista da subordinação das práticas de ensino à atividade de aprendizagem e às ações do aprender e do pensar. Sendo assim, o que se espera da aprendizagem dos alunos também deverá ser esperado de um programa de formação dos próprios professores. Tais mudanças correspondem à expectativa de DAVYDOV de que a escola de hoje ensine aos alunos a orientar-se independentemente na informação científica e em qualquer outra, ou seja, que os ensine a pensar, mediante um ensino que impulsione o desenvolvimento mental. (DAVYDOv, 1988, p. 3)

Este texto visa explorar as contribuições teóricas recentes da concepção histórico-social da aprendizagem, em especial da teoria do ensino desenvolvimental de DAVYDOv e da teoria da atividade, para a formação inicial e continuada de professores da educação básica. Essas teorias podem motivar especialmente aqueles investigadores dos campos da didática e da formação de professores convencidos da relevância da formação teórica dos professores, da necessidade de adquirirem maior efetividade no uso das instrumentalidades do trabalho docente e da importância dos contextos culturais e institucionais em que se dão o ensino e a aprendizagem. 


\section{Um olhar histórico da psicologia histórico-cultural e da teoria da atividade}

As posições teóricas da concepção histórico-cultural de VYGOTSKY (18961934), dentro da tradição da filosofia marxista, centram-se na afirmação do condicionamento histórico-social do desenvolvimento do psiquismo humano, que se realiza no processo de apropriação da cultura mediante a comunicação entre pessoas. Tais processos de comunicação e as funções psíquicas superiores neles envolvidas se efetivam primeiramente na atividade externa (interpessoal) e, em seguida, na atividade interna (intrapessoal) regulada pela consciência, mediados pela linguagem, em que os signos adquirem significado e sentido (VYGOTSKY, 1984, p. 59-65).

Essa formulação realça a atividade sócio-histórica e coletiva dos indivíduos na formação das funções mentais superiores, portanto, o caráter de mediação cultural do processo do conhecimento e, ao mesmo tempo, a atividade individual das aprendizagens pela qual o indivíduo se apropria da experiência sociocultural como ser ativo. Dessa forma, a educação e o ensino se constituem formas universais e necessárias do desenvolvimento mental.

A teoria histórico-cultural da atividade desenvolveu-se nos trabalhos de LURIA, RUBINSTEIN e LEONTIEV, continuada depois por GALPERIN e DAVYDOV, entre outros, e admite-se, em geral, que surge como um desdobramento da concepção histórico-cultural. Ela expressa a teoria psicológica da atividade formulada por LEONTIEV e desenvolvida por seus seguidores. No cerne dessa teoria, está presente a concepção marxista da natureza histórico-social do ser humano. A atividade representa a ação humana que mediatiza a relação entre o homem, sujeito da atividade, e os objetos da realidade, dando a configuração da natureza humana. Entretanto, o desenvolvimento da atividade psíquica, isto é, dos processos psicológicos superiores, tem sua origem nas relações sociais que o indivíduo estabelece com o mundo exterior, ou seja, com seu contexto social e cultural. Segundo LEONTIEv, o estudo do desenvolvimento psíquico humano encontrou sua expressão na concepção da atividade psíquica como uma forma peculiar de atividade, "como um produto e um derivado da vida material, da vida externa, que se transforma em atividade da consciência" (LEONTIEV, In DAVYDOv, 2002, p. 52). A teoria histórico-cultural da atividade tem, assim, como tarefa central, investigar a própria estrutura da atividade e sua interiorização.

No período de 1930-40, LEONTIEV (1903-1979) dedicou-se a pesquisar a estreita vinculação dos processos internos da mente com a atividade humana 
concreta. No processo da relação ativa do sujeito com o objeto, a atividade se concretiza por meio de ações, operações e tarefas, suscitados por necessidades e motivos. LEONTIEV preocupou-se especialmente com o conceito de internalização e com o papel da cultura no desenvolvimento das capacidades humanas. Na seqüência desses estudos, outros pesquisadores dedicaram-se ao desenvolvimento da teoria da atividade, entre outros, GALPERIN (Psicologia Infantil), BOZHOVICH (Psicologia da personalidade), ELKONIN (Psicologia evolutiva e periodização do desenvolvimento humano), zAPOROYETZ (Psicologia evolutiva), LEvina (Psicologia da Educação). A partir dos anos 1960, ocorre a expansão da teoria da atividade para os Estados Unidos, América Latina e norte da Europa ${ }^{1}$. No Brasil, os estudos e pesquisas sobre a teoria de VYGOTSKY tiveram um considerável desenvolvimento desde a segunda metade dos anos 1980, apresentando hoje vasta bibliografia. Em relação à produção da segunda e terceira geração de pesquisadores russos, incluindo Davydov, as pesquisas são mais raras, embora as existentes sejam bastante vigorosas ${ }^{2}$.

Trabalhos recentes têm discutido posições teóricas da psicologia histórico-cultural e da teoria da atividade, mostrando os pontos em comum e as divergências. Para Kozulın, boa parte das divergências giram em torno do problema da internalização e da relação entre a atividade externa da criança e as operações mentais correspondentes, questões que teriam gerado

${ }^{1}$ Os estudos teóricos de autores dessa região da Europa têm trazido substantivas contribuições à teoria da atividade, realçando temas como atividade situada em contextos, a participação como condição de compreensão na prática (como aprendizagem), identidade, papel das práticas institucionalizadas nos motivos dos alunos, a diversidade cultural etc. Para um levantamento recente dessas tendências, veja-se: ChaikLin. S. HEDEGAARD, M. e JENSEn, U.J. Activity theory and social practice: cultural-historical Approaches, Aarthus (Dinamarca): Aarthus Universitty Press, 1999, que traz textos preparados para o Primeiro Congresso da Sociedade Internacional sobre Teoria da Atividade e Pesquisa Cultural (ISCRAT). O nome dessa Sociedade mudou, recentemente, para International Society for Cultural and Activity Research (ISCAR). Na Universidade de Helsinki, Finlândia, funciona o Centro para Teoria de Atividade e Pesquisa de Trabalho Desenvolvimental, fundado em 1994, que realiza pesquisa sobre trabalho, tecnologia e organizações que estão passando por transformações, dirigido atualmente por Yrjo Engestrõm.

${ }^{2}$ O Grupo de Estudos sobre Teoria da Atividade, da Faculdade de Educação da USP, coordenado pelo Prof. Manoel Oriosvaldo de Moura, realiza encontros de estudos e debates sobre pesquisas de professores e alunos nessa linha. Registre-se, também, que a teoria da atividade, na versão de LEONTIEV (1983) e seguidores, tem sido largamente utilizada em Cuba por professores dedicados à metodologia do ensino superior, que inclusive a tem difundido em países latinoamericanos em cursos de Pós-Graduação realizados por convênio com instituições universitárias, inclusive brasileiras. Outros estudos no Brasil têm destacado as idéias de vYGOTSKY e seus seguidores para uma proposta de ensino, por exemplo, SAVIANI (1994), MOURA (2002), GASPARIN (2002), DUARTE (2003), SFORNI (2003). 
distanciamento do grupo liderado por LEONTIEV em relação às idéias de VYGOTSKY (2002). ZINCHENKo (1998) reconhece a existência de duas linhas de pesquisa dentro da mesma escola: a psicologia histórico-cultural de VYGOTSKY e a teoria psicológica da atividade de LEONTIEv, com pontos de convergência e de diferenças. Segundo esse autor:

A principal diferença é que para a psicologia histórico-cultural, o problema central foi e continua sendo a mediação da mente e da consciência. Para a teoria psicológica da atividade, o problema central era a orientação-objeto, em ambas as atividades mentais interna e externa. É claro que na teoria psicológica da atividade a questão mediação também apareceu, mas enquanto que para VYGOTSKY a consciência era mediada pela cultura, para LEONTIEV a mente e a consciência eram mediadas por ferramentas e objetos (ZINCHENKO, 1998, p. 44).

Tais diferenças de abordagem, acentuando-se ora o significado ora a ação, ora a atividade orientada a objetos ora o sentido são, obviamente, de cunho filosófico, gerando diferentes conseqüências teóricas e práticas. DANIELS (2003) distingue, a partir de uma base comum de idéias associadas a VYGOTSKY, a abordagem da aprendizagem situada em contextos particulares e a abordagem da cognição distribuída assentada nas relações entre o funcionamento cognitivo interno e a cultura. Também LAVE (2001) identifica diferentes interpretações da teoria da atividade. ZINCHENKO sugere que se dê continuidade às pesquisas e que olhemos para as duas linhas como complementares, uma se enriquecendo na outra, até que se possa chegar ao desenvolvimento de uma psicologia histórico-cultural da consciência e da atividade.

\section{A aprendizagem escolar como atividade}

A associação da psicologia histórico-cultural e da teoria da atividade com a educação tem sido uma constante nessas linhas investigativas, ampliando a compreensão das relações entre cultura, aprendizagem e desenvolvimento humano. $\mathrm{O}$ ensino e a educação são vistos como formas sociais de 
organização do processo de apropriação, pelo homem, das capacidades formadas sócio-historicamente e objetivadas na cultura material e espiritual. Mas para que isso aconteça é necessário que o sujeito realize determinada atividade, dirigida à apropriação da cultura. LEONTIEV escreve que a apropriação "é o processo que tem por resultado a reprodução, pelo indivíduo, das capacidades e procedimentos de conduta humanas, historicamente formados" (DAVYDOV, 2002, p. 55) ${ }^{3}$. Segundo LEONTIEV, toda ação humana está orientada para um objeto e, sendo assim, a atividade tem um caráter objetal. Ao buscar apropriar-se do objeto, mediante ações, o ser humano se aproxima das propriedades e das relações com os objetos e, dessa forma, vai construindo as imagens correspondentes a esse objeto. Isso constitui o processo de internalização da atividade externa.

A estrutura da atividade é constituída pelas necessidades, motivos, finalidades e condições de realização da atividade ${ }^{4}$. A atividade surge de necessidades, as quais impulsionam motivos orientados para um objeto. $\mathrm{O}$ ciclo que vai de necessidades a objetos se consuma quando a necessidade é satisfeita, sendo que o objeto da necessidade ou motivo é tanto material quanto ideal. Para que esses objetivos sejam atingidos, são requeridas ações. O objetivo precisa sempre estar de acordo com o motivo geral da atividade mas são as condições concretas da atividade que determinarão as operações vinculadas a cada ação. Segundo LEONTIEv:

(A atividade se refere) "àqueles processos que, realizando as relações do homem com o mundo, satisfazem uma necessidade especial correspondente a ele. (...) Por atividade, designamos os processos psicologicamente caracterizados por aquilo que o processo, como um

\footnotetext{
${ }^{3}$ A expressão "atividade reprodutiva", presente nos trabalhos de LEONTIEv e DAVYDOv, não deve ser interpretada como imitação, repetição, memorização como na linguagem usual. A atividade, no sentido marxista, nunca seria uma reprodução mecânica de ações. Conforme registra CHAIKLIN (2003): "Em suas ações únicas ou singulares, a pessoa reproduz a atividade que organiza suas ações. LEONTIEV e DAVYDOV utilizam esta expressão para enfatizar que não se trata da criação de uma atividade 'nova', mas de uma 'versão' nova (...) Penso que 'reprodução' deve ser interpretada aqui para significar que a pessoa recria as práticas humanas historicamente desenvolvidas. Por exemplo, quando alguém aprende aritmética há, até certo ponto, uma reprodução de práticas historicamente desenvolvidas, mesmo que haja pequenas variações em como um indivíduo percebe a prática objetiva". Poder-se-ia dizer, como LEONTIEv, que os indivíduos realizam uma atividade prática ou cognoscitiva ou cognitiva adequada à atividade humana precedente encarnada neles.

${ }^{4}$ A estrutura geral da atividade é tratada por LEontiev em seu livro Actividad, Conciencia y Personalidade, p. 82-100.
} 
todo, se dirige (i.e, objeto), coincidindo sempre com o objetivo que estimula o sujeito a executar essa atividade, isto é, o motivo". (LEONTIEV, 1992, p. 68)

Há, pois, uma dependência do objetivo em relação ao motivo, ou seja, a atividade implica um sentido. Por sua vez, a ação "é um processo cujo motivo não coincide com seu objetivo, mas reside na atividade da qual faz parte". Conforme explica LEONTIEv, a atividade de ler o livro somente para passar no exame, não é atividade, é uma ação, porque ler o livro por ler não é um objetivo forte que estimula a ação. A atividade é a leitura do livro por si mesmo, por causa do seu conteúdo, ou seja, quando o motivo da atividade passa para o objeto da ação, a ação transforma-se numa atividade. É isso que pode provocar mudanças na atividade principal.

As operações consistem no modo de execução de uma ação, é o conteúdo necessário de qualquer ação, determinada pela natureza da tarefa. "Uma mesma ação pode ser efetuada por diferentes operações, mas uma mesma operação também pode realizar diferentes ações, porque uma operação depende das condições em que o alvo da ação é dado, enquanto uma ação é determinada pelo alvo" (LEONTIEV, 1992, p. 74). LEONTIEV exemplifica essa relação entre ação, tarefa e condições numa situação em que o objetivo é decorar versos. A ação é a memorização dos versos e, para isso, posso agir de duas maneiras. Se a pessoa estiver sentada em casa, talvez prefira escrevêlos; em outras condições, poderá recorrer à repetição mental dos versos. Nos dois casos, a ação é a memorização, mas os meios de executá-la, isto é, as operações, serão diferentes.

A atividade humana é global, mas ela se desdobra em distintos tipos concretos de atividade, cuja diferenciação é dada pelo seu conteúdo objetal. Segundo LEONTIEV, cada tipo de atividade possui um conteúdo perfeitamente definido de necessidades, motivos, tarefas e ações. Por exemplo, o conteúdo objetal da atividade do jogo é substancialmente diferente da atividade de estudo ou da atividade profissional. "O que distingue uma atividade de outra é o objeto da atividade (...) que confere à mesma determinada direção". (LEONTIEV, 1983 , p. 83)

GALPERIN traz importantes contribuições para a sistematização da teoria da atividade, tendo formulado a teoria da formação das ações mentais. Segundo esse autor, com base em LEONTIEv, a assimilação de conhecimentos é um tipo de atividade e, para realizá-la, é requerida uma seqüência de etapas de ações mentais. O papel do professor é o de organizar e estruturar correta- 
mente a atividade de assimilação do estudante, formulando objetivos a partir das ações que deve realizar no marco das matérias de estudo e das funções que estas desempenham no perfil profissional e no currículo, selecionando os conteúdos que assegurem a formação dos conhecimentos e características da personalidade necessárias para a realização dos diferentes tipos de atividade, organização do processo de aprendizagem com base nos componentes funcionais da atividade: orientação, execução e controle ${ }^{5}$. Assumindo o entendimento de que toda atividade humana está dirigida a um objetivo, o conceito de orientação da atividade é a pedra angular da teoria de GALPERIN, pois dela depende a eficácia da ação formadora, portanto, da aprendizagem.

V. DAVYDOV contribui consideravelmente para caracterizar a atividade de aprendizagem na escola. Dando seqüência às pesquisas de seus predecessores, afirma que a aprendizagem é a atividade principal das crianças em idade escolar e sua função é a de propiciar a assimilação das formas de consciência social mais desenvolvidas - a ciência, a arte, a moralidade, a lei. O conteúdo da aprendizagem é o conhecimento teórico, pois a base do ensino desenvolvimental é seu conteúdo, do qual derivam os métodos para organizar o ensino ${ }^{6}$ :

Esta proposição exemplifica o ponto de vista de VYGOTSKY e ELKONIN. 'Para nós, escreveu ELKONIN, tem importância fundamental sua idéia (de VYGOTSKY - VD) de que o ensino realiza seu papel principal no desenvolvimento mental, antes de tudo, por meio do conteúdo do conhecimento a ser assimilado'. Concretizando esta proposição, devese observar que a natureza desenvolvimental da atividade de

5 Referindo-se a esses três elementos da atividade estabelecidos por GALPERIN, DAVYDOv destaca o papel da execução, já que ela é propriamente a atividade que assegura atingir o objetivo e satisfazer uma necessidade. Mas destaca também o papel do controle, por estar associado à atenção e, portanto, à vontade. "A atenção (...) é um mecanismo de controle que funciona no processo de conscientização do plano para que se possa atingir um objetivo, e está relacionada com a vontade". (DAVYDOv, 1999). A nosso ver, o que está sendo posto nessa interpretação é o papel sumamente relevante da orientação da atividade e dos motivos de ação.

${ }^{6}$ A maior parte das citações de DAVYDov, a seguir, são extraídas de sua obra Problems of Developmental Teaching, publicada em três números da Revista Soviet Education (Davydov, 1988 a, 1988b, 1988c), todas elas traduzidas pelo autor deste artigo. Os textos publicados nessa revista não correspondem à obra completa publicada originalmente em russo. Todavia, a tradução do inglês foi cotejada com a tradução espanhola da obra original cujo título é La ensenãnza escolar y el desarollo psíquico (1988). Registre-se, também, que todas as citações extraídas de obras publicadas em espanhol foram traduzidas pelo autor. 
aprendizagem no período escolar está vinculada ao fato de que o conteúdo da atividade acadêmica é o conhecimento teórico. (DAVYDOv, 1988b, p. 19).

Para que isso ocorra faz-se necessária uma estrutura da atividade do aprender incluindo uma tarefa de aprendizagem, as ações de aprendizagem e ações de acompanhamento e avaliação, visando à compreensão do objeto de estudo em suas relações. O resultado disso é que os alunos aprendem como pensar teoricamente a respeito de um objeto de estudo e, com isso, formam um conceito teórico apropriado desse objeto para lidar praticamente com ele em situações concretas da vida. A educação escolar constitui-se numa forma específica de atividade do aluno - a atividade de aprendizagem - cuja meta é a própria aprendizagem, ou seja, o objetivo do ensino é ensinar aos estudantes as habilidades de aprenderem por si mesmos, ou seja, a pensar. Referindo-se à atividade de aprendizagem, DAVYDOv escreve que, havendo muitos tipos, aspectos e formas de atividade, não podemos tratar de sua estrutura e conteúdo de forma abstrata; é preciso estudar extensivamente cada tipo. É assim que caracteriza a atividade de aprendizagem como um dos componentes do processo ontogenético, situando-se entre as atividades de reprodução da experiência sócio-histórica da humanidade. Ele aceita a estrutura psicológica da atividade descrita por LEONTIEV, mas acrescenta o desejo como elemento dessa estrutura, "o núcleo básico de uma necessidade" (DAVYDOv, 1999, p. 40- 41). Segundo ele, por detrás das ações humanas estão as necessidades e emoções, antecedendo a ação, as relações com os outros, as linguagens.

A coisa mais importante na atividade científica não é a reflexão nem o pensamento, nem a tarefa, mas a esfera das necessidades e emoções. (...) As emoções são muito mais fundamentais que os pensamentos, elas são a base para todas as diferentes tarefas que um homem estabelece para si mesmo, incluindo as tarefas do pensar. (...) A função geral das emoções é capacitar uma pessoa a pôr-se certas tarefas vitais, mas este é somente meio caminho andado. A coisa mais importante é que as emoções capacitam a pessoa a decidir, desde o início se, de fato, existem meios físicos, espirituais e morais necessários para que ela consiga atingir seu objetivo. (DAVYDOv, p. 45) 
Dessa forma, são realçadas questões já acentuadas por VYGOTSKY sobre o papel das emoções em relação às necessidades (REY, 2000). Em discordância com LEONTIEV, DAVYDOV afirma que as ações são conectadas muito mais a necessidades baseadas em desejos do que a necessidades baseadas em motivos, embora continue destacando o papel dos motivos. A importância desse ponto de vista é óbvia, pois põe em relevo a relação entre a afetividade e a cognição e sua integração na subjetividade. Isso significa que as ações humanas estão impregnadas de sentidos subjetivos, projetando-se em várias esferas da vida dos sujeitos, obviamente também na atividade dos alunos, na compreensão das disciplinas escolares, no envolvimento com o assunto estudado.

\section{Davydov e o ensino desenvolvimental}

Em concordância com as teses de VYGOTSKY e LEONTIEV, DAVYDOV explicita a idéia de que a formação da atividade humana depende da educação e do ensino. Ao propiciarem a apropriação da atividade humana anterior, determinam os processos do desenvolvimento mental dos alunos, ou seja, a formação de capacidades mentais. Ele escreve:

Uma análise da abordagem de VYGOTSKY e LEONTIEv sobre o problema do desenvolvimento mental permite que cheguemos às seguintes conclusões. Primeiro, no sentido mais amplo, a educação e o ensino de uma pessoa não é nada mais que sua "apropriação", a "reprodução" por ela das capacidades dadas histórica e socialmente. Segundo, a educação e o ensino ("apropriação") são formas universais de desenvolvimento mental humano. Terceiro, a "apropriação" e o desenvolvimento não podem atuar como dois processos independentes, pois se correlacionam como a forma e o conteúdo de um único processo de desenvolvimento mental humano. (1988a, p. 54)

Como mostrou vYGOTSKY, as funções mentais específicas não são inatas, mas postas como modelos sociais. Por sua vez, DAVYDOv destaca a peculiaridade da atividade da aprendizagem, entre outros tipos de atividade, cujo objetivo é o domínio do conhecimento teórico, ou seja, o domínio de símbo- 
los e instrumentos culturais disponíveis na sociedade, obtido pela aprendizagem de conhecimentos das diversas áreas do saber.

O saber contemporâneo pressupõe que o homem domine o processo de origem e desenvolvimento das coisas mediante o pensamento teórico, que estuda e descreve a lógica dialética. O pensamento teórico tem seus tipos específicos de generalização e abstração, seus procedimentos de formação dos conceitos e operações com eles. Justamente, a formação de tais conceitos abre aos escolares o caminho para dominar os fundamentos da cultura teórica atual. (...) A escola, a nosso juízo, deve ensinar às crianças a pensar teoricamente. (DAVYDOv, 2002, p. 49).

Portanto, o ensino propicia a apropriação da cultura e o desenvolvimento do pensamento, dois processos articulados entre si, formando uma unidade: enquanto o aluno forma o pensamento teórico, vai desenvolvendo ações mentais, mediante a solução de problemas que suscitam a sua atividade mental. Com isso, assimila o conhecimento teórico e as capacidades e habilidades relacionadas a esse conhecimento. É o que escreve davydov:

Os conhecimentos de um indivíduo e suas ações mentais (abstração, generalização etc.) formam uma unidade. Segundo RUBinsteIn, 'os conhecimentos (...) não surgem dissociados da atividade cognitiva do sujeito e não existem sem referência a ele'. Portanto, é legítimo considerar o conhecimento, de um lado, como o resultado das ações mentais que implicitamente abrangem o conhecimento e, de outro, como um processo pelo qual podemos obter esse resultado no qual se expressa o funcionamento das ações mentais. Conseqüentemente, é totalmente aceitável usar o termo "conhecimento" para designar tanto o resultado do pensamento (o reflexo da realidade), quanto o processo pelo qual se obtém esse resultado (ou seja, as ações mentais). 'Todo conceito científico é, simultaneamente, uma construção do pensamento $e$ um reflexo do ser'. Deste ponto de vista, um conceito é, ao mesmo tempo, um reflexo do ser e um procedimento da operação mental. (DAVYDOv, 1988, p. 21)

As pesquisas de DAVYDOV tiveram origem em suas críticas à organização do ensino assentada na concepção tradicional de aprendizagem que, segundo 
ele, somente possibilita chegar ao pensamento empírico, descritivo e classificatório. Esse tipo de conhecimento adquirido por métodos transmissivos e de memorização não se converte em ferramenta cognitiva para lidar com a diversidade de fenômenos e situações que ocorrem na vida prática. Em oposição a essa concepção, propõe um ensino mais vivo e eficaz visando ao desenvolvimento do pensamento teórico. O pensamento teórico se forma pelo domínio dos procedimentos lógicos do pensamento que, pelo seu caráter generalizador, permite sua aplicação em vários âmbitos da aprendizagem. Trata-se de um processo pelo qual se revela a essência e desenvolvimento dos objetos de conhecimento e com isso a aquisição de métodos e estratégias cognitivas gerais de cada ciência, em função de analisar e resolver problemas e situações concretas da vida prática.

Para DAVYDOV, o pensamento teórico se caracteriza como o método da ascensão do abstrato para o concreto. Não se trata de pensar apenas abstratamente com um conjunto de proposições fixas, mas de uma instrumentalidade, mediante a qual se desenvolve uma relação primária geral que caracteriza o assunto e se descobre como essa relação aparece em muitos problemas específicos. Isso é, de uma relação geral subjacente ao assunto ou problema se deduzem mais relações particulares, conforme DAVYDOv:

Ao iniciar o domínio de qualquer matéria curricular, os alunos, com a ajuda dos professores, analisam o conteúdo do material curricular e identificam nele a relação geral principal e, ao mesmo tempo, descobrem que esta relação se manifesta em muitas outras relações particulares encontradas nesse determinado material. Ao registrar, por meio de alguma forma referencial, a relação geral principal identificada, os alunos constroem, com isso, uma abstração substantiva do assunto estudado. Continuando a análise do material curricular, eles detectam a vinculação regular dessa relação principal com suas diversas manifestações, obtendo, assim, uma generalização substantiva do assunto estudado.

Dessa forma, as crianças utilizam consistentemente a abstração e a generalização substantivas para deduzir (uma vez mais com o auxílio do professor) outras abstrações mais particulares e para uni-las no objeto integral (concreto) estudado. Quando começam a fazer uso da abstração e da generalização iniciais como meio para deduzir e unir outras abstrações, elas convertem a formação mental inicial num conceito que registra o "núcleo" do assunto estudado. Este "núcleo" serve, posteriormente, às crianças, como um princípio geral pelo qual elas podem orientar-se em toda a diversidade de material curricular factual que têm que assimilar, em uma forma conceitual, por meio da ascensão do abstrato ao concreto. (DAVYDOv, p. 22) 
O que se verifica nesse processo de formação do pensamento teórico é uma clara alusão ao movimento que vai do geral para o particular, encetado pelo pensamento, conforme a lógica dialética, e uma similaridade com o método genético. Com efeito, para DAVYDov (1988b, p. 24), os componentes de uma tarefa de aprendizagem apresentada pelo professor são: a) a análise do material factual para descobrir nele alguma relação geral que tenha uma conexão regular com as diversas manifestações desse material; b) a dedução, em que as crianças deduzem determinadas relações no conteúdo estudado, formando um sistema unificado dessas relações, isto é, o "núcleo" conceitual; c) o domínio do modo geral pelo qual o objeto de estudo é construído, mediante o processo de análise e síntese. Junto com isso, o método genético refere-se às condições de origem dos conceitos científicos, isto é, aos modos de atividade anteriores aplicados à investigação dos conceitos a serem adquiridos. Para isso, segundo DAVYDov, é necessário que "os alunos reproduzam o processo atual pelo qual as pessoas criaram conceitos, imagens, valores, normas". (DAVYDOV, 1988b, p. 21-22). Essas duas estratégias de ensino e aprendizagem representam o núcleo mais rico de sua abordagem teórica. Elas buscam superar a conhecida dicotomia entre a ênfase nos conteúdos escolares e o desenvolvimento dos processos mentais, ou seja, entre a formação dos conceitos científicos e o desenvolvimento das capacidades do pensar.

É clara a vinculação dessa idéia - apropriação dos modos de pensar a que as disciplinas científicas recorrem - com duas tendências fortes na pedagogia contemporânea: o método de resolução de problemas e o método do ensino com pesquisa. As ações mentais, segundo DAVYDOv, implicam a resolução de tarefas cognitivas, "que devem ser baseadas em problemas". Eis como DAVYDOV se posiciona quanto a isso:

(...) podemos entender que a implicação geral e o papel geral da tarefa de aprendizagem no processo de assimilação serão os mesmos (a princípio) que os da educação baseada em problemas. (...) Observamos que, assim como a aprendizagem, a educação baseada na resolução de problemas está internamente associada ao nível teórico da assimilação do conhecimento e pensamento teórico. (DAVYDOv, 1988b, p. 29)

A idéia do ensino com pesquisa é a de que o professor faça pesquisa enquanto ensina, presente na noção de ensino como "experimentação formativa", em que o professor intervém ativamente por meio de tarefas nos 
processos mentais das crianças e produz novas formações por meio dessa intervenção. Ou seja, não se trata do "aprender fazendo". Se for enfatizado apenas o caráter concreto da experiência da criança, pouco se conseguirá em termos de desenvolvimento mental, porque não se chega aos conceitos. Segundo DAVYDOv, "aos conhecimentos (conceitos) empíricos correspondem ações empíricas (ou formais) e aos conhecimentos (conceitos) teóricos, ações teóricas (ou substanciais)", ou seja, se o ensino nutre a criança somente de conhecimentos empíricos, ela só poderá realizar ações empíricas, sem influir substancialmente no desenvolvimento do pensamento teórico dos alunos.

\section{Perspectivas recentes da teoria da atividade: a contextualização sociocultural das práticas}

Esse tópico discute a questão da influência de fatores sociais, culturais, históricos e institucionais no desenvolvimento cognitivo, afetivo e moral dos indivíduos. As interpretações recentes da teoria da atividade dão relevo à contextualização sociocultural da atividade a partir da compreensão da aprendizagem e do desenvolvimento como processos mediados. Essa idéia, encontrada em primeira mão em vYGOTSKY, oferece os suportes teóricos para compreender a mediação cognitiva nas interações sociais. Em Pensamento e Linguagem, ele destaca a organização social da instrução, "forma única de cooperação entre a criança e o adulto, o elemento central do processo educativo; e por este processo interativo se transfere conhecimento à criança em um sistema definido", ressaltando-se, assim, o significado teórico do contexto social do pensamento para o desenvolvimento de novas formas de pensamento". (MOLL, 1990, p. 14). Portanto, no processo de escolarização, é essencial criar contextos sociais para o domínio e internalização de processos mentais, nos quais está implicada a zona de desenvolvimento próximo.

Para M. COLE, estudando as relações entre cultura e desenvolvimento cognitivo, o postulado fundamental da escola sócio-histórica é o de que as funções psicológicas humanas diferem das dos processos psicológicos de outros animais "porque estão culturalmente mediados, se desenvolvem historicamente e surgem da atividade prática". Daí são deduzidas as teses da mediação pelos artefatos culturais ideais e materiais da relação entre os seres humanos e o mundo físico e social, o papel dessa mediação cultural na modi- 
ficação das funções mentais e o vínculo dos processos psicológicos com a atividade prática. Em resumo, "a mediação cultural e o fato de que o pensamento se funde na atividade implicam a especificidade contextual dos processos mentais". (COLE, 1993, p. 111-112)

Esses autores expressam o núcleo da discussão sobre o papel da cultura sobre a cognição e os diferentes significados atribuídos aos termos "social" e "cultural". Conforme DANIELS, duas tradições vinculadas a VYGOTSKY explicam o papel da cultura na aprendizagem e no desenvolvimento, a teoria sociocultural e a teoria histórico-cultural da atividade. Ambas reconhecem o papel dos sujeitos na transformação desses fatores sociais e culturais, mas têm diferente compreensão de como esses fatores moldam a mente humana. A primeira tem como foco de análise a mediação semiótica, com destaque à fala, a segunda, a internalização da atividade humana. (DANIELs, 2003, p. 94). Essas duas interpretações são bastante conhecidas e elas se refletem nas abordagens metodológicas de pesquisa, nas práticas pedagógicas, especialmente, na compreensão dos fatores culturais na aprendizagem, com óbvias derivações para as formas de organização escolar, os currículos e a natureza das relações professor-alunos.

Na orientação que prioriza o processo de internalização, a cultura é fonte do desenvolvimento psíquico à medida que o sujeito realiza uma determinada atividade dirigida à apropriação das capacidades sociais, objetivadas em formas de instrumentos, linguagem, obras de arte etc. Essa atividade somente pode ser realizada em comunicação permanente com outras pessoas. Escreve LEONTIEV:

A comunicação em sua forma externa inicial, como aspecto da atividade conjunta das pessoas, quer dizer, em forma de "comunicação imediata" ou em forma interna, interiorizada, conforma (...) as condições indispensáveis e específicas do processo de apropriação, pelos indivíduos, dos êxitos do desenvolvimento histórico da humanidade. (DAVYDOv, 2002, p. 57)

Todavia, a comunicação da criança com outras pessoas não está mediatizada pela palavra mas pelo objeto, pois, segundo LEONTIEv, "unicamente sobre a base das ações objetais conjuntas com o adulto a criança vai dominando a linguagem, a comunicação verbal". (LEONTIEv, p. 58). O conceito de "social", portanto, envolve a atividade sócio-histórica da humanidade que 
precisa ser "internalizada" pelos indivíduos e, assim, a cultura é algo a ser reproduzido por meio da comunicação entre as pessoas. A interiorização consiste no processo de transformação da atividade coletiva em uma atividade individual, sem dar ênfase aos aspectos interacionais do próprio contexto de aprendizagem. Numa clara crítica a esse entendimento, escrevem LAVE e WENGER:

(...) o caráter social da aprendizagem consiste em sua maior parte numa "aura" de socialidade que fornece insumos para o processo de internalização visto como aquisição individualista do dado cultural. Não há nada que dê conta do lugar da aprendizagem no quadro da estrutura do mundo social. (LAVE e WENGER, 2002, p. 166)

DAVYDOV concorda em muitos pontos com LEONTIEV em relação ao processo de interiorização, mas abre possibilidades de conceber a relação entre cultura e desenvolvimento mental para além de uma relação mecânica entre o interpessoal e o intrapessoal, como se pode verificar neste trecho:

(...) no processo de comunicação, seja material ou espiritual, surge um princípio básico do qual todos estamos conscientes (...) que é o desempenho coletivo de uma certa atividade pelos indivíduos. (...) O apelo a outras pessoas ocorre na estrutura da atividade coletiva, a atividade que é provida de problemas dos indivíduos ou da equipe. A propósito, o apelo aos outros é a base da qual surgem padrões num coletivo; e os padrões são protótipos culturais. (...) Assim, no núcleo da atividade (...) temos os seguintes pontos: primeiro, a unidade da atividade consciente inclui a natureza coletiva da realização de uma atividade pelo indivíduo coletivo ou uma equipe; em outras palavras, o que chamamos de comunicação prática (metódica), no sentido literal da palavra, não no metafórico. O segundo ponto é o apelo das pessoas umas pelas outras, refletindo sobre suas próprias ações e significados e sobre ações e significados de outras pessoas. $\mathrm{O}$ terceiro aspecto do núcleo da atividade está incluído no plano ideal e na imaginação. O quarto, é a atividade consciente individual de uma pessoa individual. (DAVYDOv, 1999, p. 10-11)

A outra linha de investigação ressalta a participação, retomando a for- 
mulação de VYGOTSKY sobre as relações entre a cognição e o mundo social e cultural e destacando a importância dos fatores contextuais para o pensamento. O desenvolvimento cultural individual pressupõe a inserção dos indivíduos numa atividade sociocultural específica, a qual implica as relações interpessoais na aprendizagem, ou seja, a participação. A abordagem sociocultural, freqüentemente vinculada a J. WERTSCH (DANIELS, 2002, p. 106), investiga as relações entre o funcionamento mental e as situações culturais, privilegiando a aprendizagem situada (ou ação situada), isto é, a aprendizagem num determinado contexto de cultura, de relações, de conhecimento, ou seja, as pessoas agindo num determinado contexto particular, focando o funcionamento cognitivo mais no campo das inter-relações do que no funcionamento interno do sistema cognitivo.

Essa orientação acentua as origens socioculturais do desenvolvimento mental individual, especialmente no lugar atribuído à cultura como algo muito concreto nos processos sociais e, portanto, presente nas condições que asseguram os processos mentais individuais.

(...) o funcionamento mental humano, mesmo quando levado a cabo por um indivíduo agindo em isolamento, é inerentemente social, ou sociocultural, na medida em que incorpora ferramentas culturais socialmente evoluídas e socialmente organizadas. (WERTSCH, 2002, p. 70)

Nesse sentido, os processos de aprendizagem dependem de compreender a atividade de aprender como socioculturalmente situada. WERTSCH destaca que, em certa altura de suas pesquisas, VYGOTSKY, ainda que mantendo seu interesse na importância dos fatores intermentais (interpessoais) na formação de conceitos, muda de foco, passando a reconhecer a força dos contextos socioculturais e institucionais na formação do pensamento conceitual.

Essa mudança no foco de vYGoTSKY é uma mudança essencial por duas razões: primeiro, foi um passo rumo à análise do pensamento conceitual em termos de seus precursores intermentais. (...) Segundo, e mais importante para nossos propósitos, foi um passo rumo a reconhecer que um tratamento das origens sociais do funcionamento intramental não pode se deter no plano intermental. Ao contrário, o importante é que as 
formas de funcionamento intermental mediadas envolvidas sejam reconhecidas, elas mesmas, como socioculturalmente situadas com respeito a ambientes de atividade e os correlatos instrumentos de mediação. Essa transição (...) sugere que, em vez de ver formas particulares de funcionamento mental como características de indivíduos ou grupos de maneira geral, essas formas podem ser vistas como características de ambientes específicos. (WERTSCH, p. 77)

A perspectiva sociocultural, portanto, opta por dar mais força ao conceito de ação mediada. Mas, para além de sua determinação pelo ambiente sociocultural mais geral, ela é entendida como algo presente em situações concretas, em que os indivíduos agem em compartilhamento com as culturas particulares que os envolve. Na expressão de WERTSCH, os instrumentos de mediação e os indivíduos "estão inerentemente implicados de tal maneira que o agir é definido como "indivíduos-operando-com-instrumentos-de-mediação".

As pesquisas mais recentes sobre teoria da atividade vinculadas a pesquisadores do norte da Europa também gravitam em torno da contextualização sóciohistórica da atividade, estabelecendo estreita relação entre as pessoas que atuam e o mundo no qual atuam ${ }^{7}$. Isso significa que fatores socioculturais exercem influência decisiva sobre os motivos dos indivíduos, mas também os indivíduos intervêm no contexto, o contexto é moldado por nossas ações, pondo em relevo, portanto, a participação dos indivíduos na construção das instituições.

Isso leva a desenvolver métodos investigativos para o estudo das práticas, atendendo às ações que realizam e aos conhecimentos diretamente requeridos pela tarefa, como também os fatores socioculturais e institucionais do contexto. HEDEGAARD realiza pesquisas sobre o papel das práticas institucionais na atribuição de significado e sentido por parte dos alunos e no provimento das condições motivacionais e pedagógicas para a aprendizagem e desenvolvimento, ressaltando a participação das crianças nessas práticas:

${ }^{7}$ A relação entre os indivíduos e o ambiente e a influência mútua que daí decorre não é de forma alguma nova nas teorias da aprendizagem. O que cabe ressaltar é que na linha cognitivista as estruturas cognitivas dos indivíduos implicam ações no ambiente e vice-versa, mas dão pouca importância aos aspectos sociais e culturais. No campo da fenomenologia e da etnometodologia, os contextos se constituem como situações sociais, espaços de experiência interativa ou campos de discurso. "Isto faz com que os contextos pareçam algo que pode ser criado à vontade por duas ou mais pessoas que interagem, prescindindo das práticas materiais e das estruturas socioeconômicas enraizadas numa cultura”, ou seja, são contextos interpessoais, mas tomados como entidades lingüísticas, simbólicas, empíricas (LAVE, 2001). 
As crianças se desenvolvem por meio da participação em formas institucionalizadas de prática, caracterizadas pela comunicação e atividades compartilhadas. Estas formas de prática iniciam, mas também restringem, as atividades das crianças e, desse modo, tornam-se condições para o seu desenvolvimento. A participação de uma criança em uma atividade contribui para a realização concreta dessa atividade, a qual contribui para as condições do próprio desenvolvimento dele ou dela. (HEDEGAARD, 1999, p. 280)

Também LAVE e WENG ER (2002) defendem uma abordagem da aprendizagem como participação numa comunidade de prática. Em contraposição a uma interpretação "cultural”, pela qual a zona de desenvolvimento proximal seria concebida como a distância entre o conhecimento cultural fornecido pelo contexto sócio-histórico (tornado acessível pelo ensino) e a experiência cotidiana dos indivíduos, as autoras propõem uma noção de aprendizagem como uma parte integrante da prática social, em que mundo e atividade não se separam e onde a participação implica negociações de significado situadas no mundo.

Uma teoria da prática social enfatiza a interdependência relacional de agente e mundo, atividade, significado, cognição, aprendizagem e conhecimento. Enfatiza o caráter inerentemente socialmente negociado do significado e o caráter interessado, concernido do pensamento e das ações das pessoas-em-atividade. Esta visão também afirma que aprender, pensar e saber são relações entre pessoas em atividade no mundo, com o mundo e surgidas do mundo socialmente e culturalmente estruturado. Este mundo é constituído socialmente: formas objetivas e sistemas de atividade, de um lado, e entendimentos subjetivos e intersubjetivos dos agentes, do outro, constituem mutuamente tanto o mundo quanto suas formas experienciadas. (...) A noção de participação, assim, dissolve as dicotomias entre atividade cerebral e corporal, entre contemplação e envolvimento, entre abstração e experiência: pessoas, ações e mundo estão implicados em todo pensar, falar, conhecer e aprender". (LAVE e WENGER, p. 167-168)

Como se pode observar, há notórias diferenças nas concepções dos autores em relação à teoria da atividade. Todavia, a nosso ver, a teoria da 
aprendizagem baseada na formação do pensamento teórico pode ser complementada com as teorias da prática social, que privilegiam a participação na prática social. Segundo as autoras mencionadas, "a insistência na natureza histórica da motivação, do desejo e das próprias relações pelas quais a experiência social e culturalmente mediada está disponível para as pessoas na prática, é uma chave para os objetivos a serem cumpridos no desenvolvimento de uma teoria da prática”. Essa perspectiva enriqueceria a teoria do ensino desenvolvimental e, nesse sentido, passam a ser importantes as interlocuções, as trocas, ou seja, o compartilhamento de culturas num contexto de atividade situada, assim como as formas de organização escolar, pois "atividades, tarefas, funções e noções não existem em isolamento; são parte de sistemas de relações mais amplos nos quais elas têm significação". (LAVE; WENGER, p. 168)

Daniels discute as possibilidades de complementaridade entre os modelos de desenvolvimento cultural, baseados na participação ou na interiorização, citando MATusov: "avalio a visão de mundo da interiorização como um parceiro dialógico que estimula e até mesmo molda o desenvolvimento do modelo de participação" (DANIELs, 2003, p. 57).

Nessa mesma direção, embora partindo da perspectiva davydoviana, parece caminhar a proposta de HEDEGAARD. Ela propõe uma conceituação do ensino e da aprendizagem como um duplo movimento entre a atividade situada e os conceitos das disciplinas:

O planejamento do professor deve avançar das leis gerais para a realidade circundante em toda a sua complexidade (...) a aprendizagem das crianças deve se desenvolver das ações preconcebidas para a simbolização do conhecimento que obtêm por meio de sua pesquisa, resultando finalmente numa formulação lingüística de relações. As atividades iniciais devem ser orientadas para a investigação concreta. Em nosso experimento didático, tais atividades incluem análise investigativa de objetos, visitas a museus e filmes. (...) Há, portanto, um movimento duplo no ensino: o professor deve guiar o ensino com base nas leis gerais, enquanto as crianças devem se ocupar com essas leis gerais na forma mais clara possível por meio da investigação da manifestação dessas leis. (HEDEGAARD, 2002, p. 210)

Parece-nos, pois, possível compreender a perspectiva da internalização na dialética entre o externo e o interno como um pressuposto da perspectiva 
de participação. Por um lado, há que se considerar que existem estruturas sociais objetivas que se sobrepõem às situações imediatas e às interações sociais que ocorrem no interior delas. Daí decorre, por exemplo, o estabelecimento de objetivos sociais e políticos para o ensino a partir de necessidades coletivas da sociedade como um todo. Mas, por outro, a atividade de ensino depende, sim, de seus contextos socioculturais e institucionais como propiciadores dos instrumentos de cognição e linguagem.

\section{A formação profissional de professores como atividade de aprendizagem em contextos socioculturais}

As concepções de ensino e aprendizagem da teoria histórico-cultural formuladas inicialmente por VYGOTSKY, a teoria do ensino desenvolvimental de DAVYDOv e a teoria histórico-cultural da atividade, trazem relevantes contribuições aos projetos de formação de professores. Os estudos e pesquisas sobre a teoria de VYGOTSKY e sua aplicação à aprendizagem escolar tiveram um desenvolvimento intenso no Brasil desde a segunda metade dos anos 1980, não tendo ocorrido o mesmo em relação à sua aplicação à formação de professores. As considerações a seguir visam apontar algumas contribuições das teorias de VYGOTSKY e de DAVYDOV e da teoria da atividade para propostas de currículos e metodologias de formação inicial e continuada de professores.

A teoria de VYGOTSKY tem como premissa básica o condicionamento histórico-social da formação humana e, portanto, o destaque do papel decisivo da atividade coletiva dos indivíduos na formação das funções mentais superiores. Ressalta-se, assim, o papel da mediação cultural no processo do conhecimento e, ao mesmo tempo, a atividade individual de aprendizagem para apropriação ativa da experiência sociocultural da humanidade, mediada pela comunicação e pelas relações intersubjetivas. A educação, assim, é um processo de apropriação de signos culturais enquanto "instrumentos psicológicos" que ajudam os indivíduos a organizar seu comportamento e suas ações, através do processo de internalização (VYGOTSKY, 1984).

DAVYDOV, com sua teoria do ensino desenvolvimental, amplia as idéias de VYGOTSKY. Conforme já mencionado anteriormente, o conteúdo da atividade escolar é o conhecimento teórico-científico e as capacidades e hábitos correspondentes a esse conhecimento, ou seja, a base do ensino desenvolvimental é o seu conteúdo, dos quais são extraídos os métodos e a organização do 
ensino. DAVYDOv não investigou diretamente a aplicação de sua teoria à formação de professores, mas sendo seu objetivo aprofundar a compreensão da aprendizagem como atividade, isso nos permite compreender a formação de professores como aprendizagem. Seguiremos neste artigo as posições do autor dinamarquês Seth chaikLIN, cujas pesquisas destinam-se a verificar se os pressupostos do ensino desenvolvimental são aplicáveis para alunos pós-educação básica.

Para CHAIKLIN, os dois elementos centrais no ensino desenvolvimental são a análise do conteúdo e os motivos da aprendizagem. A análise do conteúdo consiste em verificar a espinha dorsal de conceitos a partir de um conceito-chave, de tal modo que o professor possa extrair uma estrutura de tarefas de aprendizagem compatíveis com os motivos do aluno. "O compromisso simultâneo do assunto com os motivos é uma hipótese que pode ser considerada como o coração do ensino desenvolvimental" (CHAIKLIN, 2003). Essa dupla característica promove a ligação entre o conhecimento teórico e o desenvolvimento da personalidade, i.e., entre ensino e educação.

Todavia, de acordo com a teoria do ensino desenvolvimental, o desenvolvimento ocorre quando o ensino é formulado em relação à atividade principal dos alunos. Nesse caso, os autores russos que estudam a periodização dos estágios do desenvolvimento entendem que, para alunos que concluíram a educação básica, a atividade de aprendizagem já foi adquirida e não é mais a atividade principal. Entretanto, CHAIKLIN precisamente desenvolveu pesquisa para comprovar que a análise de conteúdo ainda é necessária para estudantes pós-educação básica e o ensino pode ser desenvolvimental, mesmo que a atividade principal desses alunos não seja a atividade de aprendizagem, e que o papel e o significado da análise do assunto podem ser melhor apreciados tendo como pano de fundo a atividade de aprendizagem. Ou seja, a atividade de aprendizagem ainda ocupa uma boa parte do trabalho desses alunos.

Conhecimento teórico ou pensamento teórico, na acepção de DAVYDOV, refere-se à capacidade de desenvolver uma relação principal geral que caracteriza um conteúdo e aplicar essa relação para analisar outros problemas específicos desse conteúdo. Esse processo produz um número de abstrações cuja intenção é integrá-las ou sintetizá-las como conceitos. Segundo cHAIKLIN:

O propósito da atividade de aprendizagem é ajudar os alunos a dominar as relações, abstrações e generalizações e sínteses que caracterizam um aspecto da matéria. Este domínio é refletido na sua habilidade para fazer reflexão substantiva, análise e planejamento. A estratégia educacional 
básica para dar aos alunos a possibilidade para reproduzir pensamento teórico é criar tarefas instrucionais cujas soluções requeiram a formação de abstrações substantivas e generalizações sobre as idéias centrais do assunto. Esta aproximação é fundamentada na idéia de VYGOTSKY de internalização, ou seja, aprende-se o conteúdo da matéria aprendendo os procedimentos pelos quais se trabalha na matéria de estudo. (CHAIKLIN, 2003)

Essas considerações nos remetem, pois, inicialmente, a dois requisitos de um programa de formação de professores: a) a análise do conteúdo da formação dos alunos, implicando os conteúdos das matérias formativas e os procedimentos pelos quais se trabalha essas matérias; 2) as motivações dos alunos, considerando-se a estrutura da atividade nesse nível de formação, em que se combina a atividade profissional e a atividade de aprendizagem.

Aplicando o ensino desenvolvimental à formação de professores, a atividade de aprendizagem da profissão consiste em que os professores adquiram conhecimento teórico, isto é, que reproduzam conscientemente as compreensões teóricas desenvolvidas em uma matéria, de modo a poder explicar as importantes relações estruturais que caracterizam essa matéria. Com efeito, se a atividade principal do futuro professor é a de promover a atividade de aprendizagem de seus futuros alunos, nada mais oportuno que o professor aprenda sua profissão na perspectiva em que irá ensinar aos seus alunos. Além disso, sendo correto entender que a base do ensino desenvolvimental é a estrutura psicológica da atividade, com base na qual são criadas tarefas para melhor promover a aprendizagem, será importante estabelecer as características da atividade profissional do professor, de modo que isso se constitua como referência para o currículo.

Cumpre destacar, ainda, a importância do desenvolvimento dos processos do pensar em relação aos conteúdos. Sabe-se que são consideráveis as deficiências do professorado em relação ao aprender a pensar ${ }^{8}$, de modo que eles próprios necessitam dominar estratégias de pensar e de pensar sobre o

${ }^{8}$ Ensinar a pensar, aprender a pensar, são expressões utilizadas aqui no sentido que pode ser captado na teoria histórico-cultural de VYGOTSKY e na obra de DAVYDOv, de que a escola é lugar de mediação cultural de significados. A escolarização significa a apropriação de significados sociais com sentido pessoal e, para que isso ocorra, é preciso aprender a pensar, é preciso propiciar mediações cognitivas. A aprendizagem do pensar inclui o aprender a aprender, cujo pleno sentido é saber buscar informação, desenvolver autonomia de pensamento, desenvolver recursos próprios para uma educação continuada. 
próprio pensar. A teoria do ensino desenvolvimental é compatível com essa demanda, pois possibilita a aquisição do conhecimento teórico e das ferramentas cognitivas, desenvolvendo as competências do pensar. Trata-se, pois, da necessidade da reflexão sobre a prática a partir da apropriação de teorias como marco para as melhorias das práticas de ensino, em que o professor é ajudado a compreender o seu próprio pensamento, a refletir de modo crítico sobre sua prática e, também, a aprimorar seu modo de agir, seu saber-fazer, à medida que internaliza novos instrumentos de ação.

A teoria histórico-cultural da atividade, em suas várias interpretações, também traz importantes contribuições na configuração dos elementos necessários à atividade profissional dos professores. Com base nessa teoria, o princípio dominante na formação não seria em primeiro lugar a reflexão em si mesma, mas a atividade de aprendizagem, ou melhor, a atividade pensada de aprender, com todos os desdobramentos que isso implica, em termos de teorias do ensino e da aprendizagem. O tornar-se professor é uma atividade de aprendizagem e, para isso, são requeridas capacidades e habilidades específicas. A atividade de aprendizagem estaria ligada aos fazeres que seriam o suporte do desenvolvimento do pensamento teórico. BRUNER acrescenta sobre isso as seguintes considerações:

(...) a mente humana constitui uma extensão das mãos e das ferramentas que você utiliza e das funções às quais você os aplica. (...) Freqüentemente sabemos fazer as coisas muito antes de conseguirmos explicar conceitualmente o que estamos fazendo ou, normativamente, por que deveríamos estar fazendo-as. (...) O trabalho ou a atividade, ou, de maneira geral, a prática, fornece um protótipo de cultura. (BRUNER, 2001, p. 146)

O autor quer dizer que a cultura fornece "as coisas" (ferramentas, práticas, modos de agir) que mobilizam nossa atividade cognitiva e nosso desenvolvimento cognitivo e que "nossas formas de fazer as coisas habilmente refletem formas implícitas de se afiliar à cultura que muitas vezes vão além do que "sabemos" de forma explícita.

Vimos que, para LEONTIEV, uma atividade se distingue de outra pelo seu objeto, e que a atividade se realiza mediante as ações, de modo que a atividade humana não pode existir a não ser em forma de ações ou grupos de ações, de modo que a atividade laboral se manifesta em ações laborais, a atividade 
didática em ações de aprendizagem, a atividade de comunicação em ações de comunicação. "Quando se desenvolve diante de nós um processo concreto, externo ou interno, na sua relação com o motivo, este se manifesta como uma atividade humana; e no que se refere à subordinação ao objetivo, como ação ou grupo de ações". (LEONTIEv, 1983, p. 85). Sendo assim, tanto a atividade profissional quanto a atividade cognitiva implicam o desenvolvimento de ações muito específicas, obrigando-nos a não tratar a atividade docente como algo abstrato mas como atividade que requer instrumentalidades.

Consideramos, pois, que o professor desenvolve uma atividade prática, entendendo prática no sentido de envolver uma ação intencional marcada por valores. O professor pode aprimorar seu trabalho apropriando-se de instrumentos de mediação desenvolvidos na experiência humana. Não se trata de voltar ao tecnicismo, mas de associar de modo mais efetivo o modo de fazer e o princípio teórico-científico que lhe dá suporte. Segundo FELDMAN, não se trata de acreditar que novas teorias ou bons princípios levam, necessariamente, a mudanças na prática nem que a revisão das práticas aconteça por um trabalho de reflexão sistemática.

(Uma abordagem instrumental) sustenta que novas compreensões serão possíveis, desde que os princípios básicos estejam expressos em instrumentos adequados e possam ser utilizados em um ambiente significativo, sustentado pela participação de pessoas com diferentes graus de conhecimento e operação desse tipo de tarefa e de seus fundamentos. (FELDMAN, 2001, p. 111)

O trabalho de professor é, portanto, um trabalho prático, entendido em dois sentidos, o de ser uma ação ética orientada para objetivos (envolvendo, portanto, reflexão) e o de ser uma atividade instrumental adequada a situações. A reflexão sobre a prática não resolve tudo, a experiência refletida não resolve tudo. São necessárias estratégias, procedimentos, modos de fazer, além de um sólido conhecimento teórico, que ajudam a melhor realizar o trabalho e melhorar a capacidade reflexiva sobre o que e como mudar. FELDMAN escreve que é possível propor um enfoque instrumental que não seja tecnicista, desde que instrumental seja entendido como o desenvolvimento de meios para obtenção de algum objetivo. 
Este enfoque sugere que é possível aumentar nossa capacidade para uma prática mais consciente, racional e autônoma mediante processos significativos, assentados em uma recriação das possibilidades através da busca e da utilização prática de instrumentos didáticos (modelos de ensino, estratégias, técnicas específicas etc.). Defendo que um enfoque instrumental não é tecnicista porque recupera a dimensão prática da tarefa de ensino e a deliberação prática em âmbitos coletivos. (FELDMANN, p. 113)

Também MOURA assume a posição de que o professor pode aprender o saber fazer, e aposta numa teoria que possa servir e servir-se da prática de ensinar.

(...) o aprender fazer do professor pode ser aprendido a partir do pressuposto da didática de que é possível a organização de processos de ensino mais eficientes que outros. (...) Da perspectiva que o conhecimento acontece em terreno interindividual (BAKHTIN) e em atividades que satisfazem a necessidades (LEONTIEV), desenvolveremos a idéia de atividade orientadora do ensino, como unidade de formação do aluno e do professor. (MOURA, 2002, p. 144)

O autor acrescenta que a organização de princípios norteadores das ações do professor depende de compreender o ensino como objeto principal da atividade docente, decorrendo daí as ações e operações a serem realizadas, por meio da atividade orientadora do ensino, a execução e o controle (MOURA, 2002, p. 154-160)

Mencionamos anteriormente as contribuições recentes da teoria da atividade relacionadas com o entendimento da atividade docente como prática coletiva que ocorre em contextos socioculturais e institucionais. Nessa perspectiva, não basta buscar o conhecimento teórico e os meios pedagógicodidáticos de melhorar e potencializar a aprendizagem dos professores pelas competências do pensar, é preciso considerar os contextos concretos em que se dá a formação. O trabalho de professor ocorre num marco institucional, expresso nas formas de organização da escola, por sua vez inserido em contextos políticos e socioculturais. Há uma inter-relação entre as pessoas que atuam e o contexto de sua atividade, havendo uma mudança tanto nas pessoas quanto nos contextos, de modo que "a participação na vida cotidiana pode ser 
concebida como um processo de cambiante compreensão na prática, ou seja, como aprendizagem". (LAVE, 2001, p. 25)

É necessário, assim, na investigação sobre formação de professores, a análise das práticas sociais, especialmente aquelas estruturadas em práticas institucionais. (ENGESTRÕM, 2002; HEDEGAARD, 1999, 2002; LAVE e WENGER, 2002; CHAIKLIN, 2003a). No caso da escola, pode-se analisar essas práticas nas quais estão presentes as condições motivacionais, as formas de organização da escola e do ensino, as intervenções pedagógico-didáticas. Essa linha de investigação é compatível, também, com estudos que associam a organização escolar à cultura da escola, em que os aspectos culturais se tornam presentes na cultura organizacional ou na comunidade de aprendizagem. (FORQUIN, 2000; LIBÂNEO, 2002; CANÁRIO, 1997; LIPMAN, 1997; PÉREZ GÓMEZ, 1998; ABDALLA, 2000; MOURA, 2003)

Segundo moura, o espaço escolar propicia aos professores elementos de formação provenientes não só da coletividade existente na própria escola, mas de outros espaços de convívio social. Isso significa que o corpo docente de uma escola entra em interação com crenças, valores, conhecimentos, habilidades etc., que passaram a fazer parte do conhecimento do coletivo a ser usado em novas ações. (MOURA, 2003, p. 137). LAVE e WENGER desenvolvem essa idéia, acentuando a relação entre a atuação das pessoas e os ambientes:

Achamos que é importante considerar como sistemas de significado cultural compartilhados e estruturas político-econômicas estão interrelacionados, em geral, e como ajudam a co-constituir a aprendizagem em comunidades de prática. (2002, p. 171)

Podemos entender, pois, a atividade profissional do professor como uma atividade definida cultural, social e historicamente; ou seja, é uma atividade socialmente situada, razão pela qual os próprios professores aprendem no contexto de trabalho em parceria com seus colegas, na dependência de estruturas de organização e gestão, das relações internas, da cultura organizacional, das ações de assistência pedagógica ao professor e da ocorrência de oportunidades de reflexão conjunta.

Considere-se, ademais, a dimensão crítica da atividade profissional que permeia todo o processo de formação, já que o processo do conhecimento é histórico, implicando uma cultura crítica em relação aos objetos de conhecimento e à atividade profissional. Pensar é mais do que explicar e para isso, as 
instituições precisam formar sujeitos pensantes, capazes de um pensar epistêmico, ou seja, sujeitos que desenvolvam capacidades básicas em instrumentação conceitual que lhes permitam, mais do que saber coisas, mais do que receber uma informação, colocar-se frente à realidade, apropriar-se do momento histórico de modo a pensar historicamente essa realidade e reagir a ela. Nesse sentido, ENGESTRÕM aponta a busca das contradições internas do sistema de atividade analisado como um dos princípios metodológicos da teoria da atividade:

Uma atividade não é um sistema estável e harmonioso. (...) Os sistemas de atividade se caracterizam por suas contradições internas. As principais contradições internas refletem a contradição básica inerente à formação socioeconômica como um todo; no capitalismo, a contradição básica é a dupla natureza das mercadorias, a tensão entre o valor de uso e o valor de troca. Nos distintos sistemas de atividade esta tensão fundamental aparece, embora sob formas diferentes, como a principal contradição. (ENGESTRÕM, 2002, p. 87)

\section{Conclusão}

As considerações que agora concluímos nos levaram a conceber a atividade profissional dos professores como o desenvolvimento simultâneo de três aspectos: o primeiro, a apropriação teórico-crítica dos objetos de conhecimento, mediante o pensamento teórico e considerando os contextos concretos da ação docente; o segundo, a apropriação de metodologias de ação e de formas de agir, a partir da explicitação da atividade de ensinar; o terceiro, a consideração dos contextos sociais, políticos, institucionais - práticas contextualizadas - na configuração das práticas escolares.

Procuramos mostrar que a psicologia histórico-cultural e a teoria histórico-cultural da atividade são teorias com grandes possibilidades de ajudar a compreender melhor o trabalho de professor e, em consequiência, sua formação profissional. Elas podem ser úteis aos pesquisadores, aos formadores de professores, às instituições formadoras e aos professores, pois trazem um referencial teórico mais abrangente, juntando os componentes da prática profissional do professor numa concepção unitária, uma vez que aborda a natu- 
reza e a estrutura da atividade humana, a atividade do ensino no desenvolvimento humano, a atividade de aprendizagem. Especialmente, possibilitam compreender a formação profissional a partir do trabalho real, das práticas correntes no contexto de trabalho e não a partir do trabalho prescrito, tal como aparece na visão da racionalidade técnica e tal como aparece também na concepção de senso comum sobre formação que ainda vigora fortemente nas escolas e nas instituições formadoras.

No Brasil, o percurso investigativo em torno dessas questões está ainda impregnado de dificuldades tanto teóricas quanto práticas, principalmente porque o campo científico e profissional da educação não tem hoje posições seguras sobre a natureza e as funções da educação escolar e, portanto, da atividade docente e dos objetivos e formas de organização da aprendizagem escolar. Trata-se de uma questão crucial pois disso dependeriam os referenciais para os programas de formação de professores, já que um dos pressupostos desse trabalho é de que o critério para organização das escolas de formação de professores deve ser pautado pelo papel que se reserva às escolas e pela concepção de aprendizagem em que se acredita.

Uma dessas dificuldades diz respeito ao dilema entre o universalismo e o relativismo, presente na educação, na cultura e na ética, atingindo diretamente as questões tratadas aqui, especialmente os objetivos da educação escolar. Refere-se, de um lado, à existência de uma cultura e de valores universais e, por outro, à consideração do pluralismo das culturas e das diferenças. Defender os conteúdos científicos e o desenvolvimento do pensamento teórico equivale a desconsiderar as culturas particulares ou a proceder a uma imposição cultural? Será possível conciliar a posição relativista, em que os valores e práticas são produtos socioculturais, portanto decorrentes do modo de pensar e agir de grupos sociais particulares, com a exigência "social" de prover a cultura geral, acessível a todos, independentemente de contextos particulares?

Desse dilema decorre outro que diz respeito a formas de organização curricular, em que se põem, de um lado, um currículo baseado na formação do pensamento científico e, de outro, um currículo baseado na experiência sociocultural. Se o dilema anterior procede bem mais do campo ético, aqui nos colocamos frente a posições em relação ao currículo e práticas escolares. No primeiro caso, o foco é colocado nas mediações cognitivas como instrumento para desenvolvimento do pensamento e, assim, o currículo e as práticas escolares estariam voltados para a internalização de elementos cognitivos, de bases conceituais, para lidar com a realidade, sem descartar a motivação do aluno, sua subjetividade e contextos de vida. No segundo, o conhecimento 
escolar estaria na experiência sociocultural, na convivência e nas práticas de socialização, isto é, a cultura "escolar" estaria subordinada aos saberes de experiência de que são portadores os alunos, dissolvendo-se a disciplinaridade em favor de um conteúdo mais próximo às manifestações culturais. Em face desse dilema, seria pedagogicamente viável prover os alunos dos conteúdos científicos sem deslegitimar os discursos dos alunos a partir de seus contextos de vida? Haverá efetiva incompatibilidade entre a aprendizagem dos conteúdos científicos associados aos processos de pensamento e à incorporação no currículo da experiência sociocultural e características sociais e psicológicas dos alunos?

São questões cruciais que antecedem as políticas de formação de professores. As idéias desenvolvidas neste texto têm como premissa o entendimento de que o trabalho pedagógico pressupõe intencionalidades políticas, éticas, didáticas em relação às qualidades humanas, sociais, cognitivas esperadas dos alunos que passam pela escola. Frente aos velhos temas da didática como a relação conteúdo e forma, a ênfase ora nos aspectos materiais ora nos aspectos formais do ensino, entre a formação cultural e científica e a experiência sociocultural dos alunos, caberia apostar na universalidade da cultura escolar, de modo que à escola caberia transmitir saberes públicos a todos, já que apresentam um valor, independentemente de circunstâncias e interesses particulares. Ao mesmo tempo, permeando os conteúdos, caberia considerar a experiência sociocultural, a diversidade e a coexistência das diferenças, a interação entre indivíduos de identidades culturais distintas.

A nosso ver, o esforço de integração entre os dilemas apontados encontra posições favoráveis nos autores abordados neste texto, por exemplo, os que consideram compatíveis a abordagem do desenvolvimento do pensamento teórico, a participação do aluno em comunidades de prática e a análise crítica da prática presente e suas contradições internas. Nesse sentido, podem se associar à teoria do ensino desenvolvimental e à teoria da atividade, as teorias que se movem em torno das noções de "prática", de cultura, de comunidade de aprendizagem, constituindo-se numa promissora contribuição à formação inicial e continuada de professores. 


\section{REFERÊNCIAS}

ABDALLA, M. F. B. Formação e desenvolvimento profissional do professor: o aprender a profissão (um estudo em escola pública). São Paulo, 2000.Tese (Doutorado) Faculdade de Educação da USP.

BARBERO, J. M. Jovenes: comunicación y identidad, 2003. Disponível em: <http:// www.campus-oei.org/pensariberoamerica/ric00a03.htm>

BELLONI, M. L. (Org.). A formação na sociedade do espetáculo. São Paulo: Loyola, 2002.

BRUNER, J. A cultura da educação. Porto Alegre: Artes Médicas, 2001.

CANÁRIO, R. A escola: o lugar onde os professores aprendem. In: CONGRESSO NACIONAL DE SUPERVISÃO NA FORMAÇÃO, 1., 1997, Lisboa. Digitado.

CHAIKLIN, S. Developmental Teaching in upper-secondary scholl. 2003a; Disponível em: <http://www.maro.newmail.ru/>

. Correspondência pessoal, 2003b.

CHAIKLIN, S.; LAVE, J. (Comps.). Estudiar las prácticas - perspectivas sobre actividad y contexto. Buenos Aires: Amorrortu Editores, 2001.

COLE, M. Desarrollo cognitivo y educación formal: comprobaciones a partir de la investigación transcultural. In: MOLL, L. C. Vygotsky y la educación. Buenos Aires: Aique, 1993.

DANIELS, H. Vygotsky e a pedagogia. São Paulo: Loyola, 2003.

. (Org.). Uma introdução a Vygotsky. São Paulo: Loyola, 2002.

DAVYDOV, V. Analisis de los princípios didacticos de la escuela tradicional y possibles princípios de enseñanza en el futuro proximo. In: SHUARE, M. La Psicologia evolutiva y pedagogia en la URSS. Antologia. Moscu: Editorial Progreso, 1987.

. Problems of developmental teaching - the experience of theoretical and experimental psychological research. Parte I - Cap. 1-The basic concept of contemporary psychology. Cap. 2-Problems of children's mental development. Revista Soviet Education, New York, Aug. 1988a.

.Problems of development teaching - The experience of theorical and experimental psychological resarch.Parte II - Cap. 5 -Learning activity in the younger school age period. Cap. 6 - The mental development of younger school children in the process of learning activity. Revista Soviet Education, New York, Sep. 1988b. 
La enseñanza escolar y el desarrollo psíquico. Prefácio. Moscu: Editorial Progreso, 1988.

A new approach to the interpretation of activity structure and Content. In: HEDEGARD, Mariane; JENSEN, Uffe Jull. Activity theory and social practice: cultural-historical approaches. Aarhus (Dinamarca): Aarthus University Press, 1999.

. El aporte de A. N. Leontiev al desarrollo de la psicología. In: GOLDER, Mário. Angustia por la utopia. Buenos Aires: Ateneo Vygotskyano de la Argentina, 2002.

. Radzikhovskii, L. A. Vygotsky theory and the activity-oriented approach in Psychology. In: WERTSCH, J. (Org.). Culture, communication and cognition: Vygotskyan perspectives. New York: Cambridge University Press, 1988.

DUARTE, N. Sociedade do conhecimento ou sociedade de ilusões: quatro ensaios crítico-dialéticos em Filosofia da Educação. Campinas: Autores Associados, 2003.

ENGESTRÕM, Y. Non scholae sed vitae discimus: como superar a encapsulação da aprendizagem escolar. In: DANIELS, Harry (Org.). Uma introdução a Vygotsky. São Paulo: Loyola, 2002.

FELDMAN, D. Ajudar a ensinar - relações entre didática e ensino. Porto Alegre: Artes Médicas, 2001.

FORQUIN, J. C. O currículo entre o relativismo e o universalismo. Educação e Sociedade, Campinas, ano 21, n. 73, dez. 2000.

GASPARIN, J. L. Uma didática para a Pedagogia Histórico-Crítica. Campinas: Autores Associados, 2002.

GOLDER, M. Angustia por la utopia. Buenos Aires: Ateneo Vygotskyano de la Argentina, 2002.

HARGREAVES, A. O ensino como profissão paradoxal. Pátio, Porto Alegre, ano 4, n. 16, fev./abr. 2001.

HEDEGAARD, M. A zona de desenvolvimento proximal como base para o ensino. In: DANIELS, Harry. (Org.). Uma introdução a Vygotsky. São Paulo: Loyola, 2002.

. Institutional practices, cultural positions, and personal motives: imigrant turkish parent's conceptions about children's school life. In: HEDEGARD, Mariane; JENSEN, Uffe Jull. Activity theory and social practice: cultural-historical approaches. Aarhus (Dinamarca): Aarthus University Press, 1999.

KOZULIN, Alex. O conceito de atividade na psicologia soviética: Vygotsky, seus discípulos, seus críticos. In: DANIELS, Harry. (Org.). Uma introdução a Vygotsky. São Paulo: Loyola, 2002. 
LAVE, Jean. La práctica del aprendizaje. In: CHAIKLIN, Seth; LAVE, Jean (Comps.) Estudiar las prácticas - perspectivas sobre actividad y contexto. Buenos Aires: Amorrortu Editores, 2001.

; WENGER, Etienne. Prática, pessoa, mundo social. In: DANIELS, Harry (Org.). Uma introdução a Vygotsky. São Paulo: Loyola, 2002.

LEONTIEV, A. N. Actividad, conciencia, personalidad. La Habana: Editorial Pueblo y Educación, 1983.

. Uma contribuição à teoria do desenvolvimento da psique infantil. In: VYGOTSKYI, L. S.; LURIA, A. R.; LEONTIEV, A. N. Linguagem, desenvolvimento e aprendizagem. São Paulo: Ícone, 1992.

LIBÂNEO, J. C. Reflexividade e formação de professores: outra oscilação do pensamento pedagógico brasileiro? In: PIMENTA, Selma G.; GHEDIN, Evandro (Orgs.). Professor reflexivo no Brasil - gênese e crítica de um conceito. São Paulo: Cortez, 2002.

LIPMAN, M. Natasha - Diálogos Vygotskyanos. Porto Alegre: Artmed, 1997.

MOLL, L. C. Introducción. In: Vygotsky y la educación. Buenos Aires: Aique, 1993.

MOURA, M. O. O educador matemático na coletividade de formação. In: TIBALLI et al. (Orgs.). Concepções e práticas em formação de professores: diferentes olhares. Rio de Janeiro: XI Endipe/DP\&A, 2003.

A atividade de ensino como ação formadora. In: CASTRO, Amélia D. de; CARVALHO, Ana Maria P. (Orgs.). Ensinar a ensinar: didática para a escola fundamental e média. São Paulo: Pioneira Thomson Learning, 2002.

MORIN, E. Os sete saberes necessários à educação do futuro. São Paulo: Cortez/ Unesco, 2000.

PÉREZ GÓMEZ, A. I. La cultura escolar en la sociedad neoliberal. Madrid: Morata, 1999.

Ensino para a compreensão. In: SACRISTÁN, G.; PÉREZ GÓMES, A. I. Compreender e transformar o ensino. Porto Alegre: Artmed, 1998.

PIMENTA, S. G. Professor reflexivo: construindo uma crítica. In: PIMENTA, Selma G.; GHEDIN, Evandro (Orgs.). Professor reflexivo no Brasil - gênese e crítica de um conceito. São Paulo: Cortez, 2002.

PORTO, T. M. E. (Org.). Redes em construção: meios de comunicação e práticas educativas. Araraquara: JM, 2003.

REY, F. G. El lugar de las emociones en la constitución social de lo psíquico: el aporte de Vygotsky. Educação e Sociedade, ano 21, n. 70, abr. 2000. 
SAVIANI, N. Saber escolar, currículo e didática - problemas da unidade conteúdométodo no processo pedagógico. Campinas: Autores Associados, 1994.

SFORNI, M. S. de Faria. Aprendizagem conceitual e organização do ensino: contribuições da teoria da atividade. São Paulo, 2003. Tese (Doutorado) - Feusp.

VYGOTSKY, L. S. A formação social da mente. São Paulo: Martins Fontes, 1984.

WERTSCH, J. V.; TULVISTE, Peeter. L. S. Vygotsky e a psicologia evolutiva contemporânea. In: DANIELS, H. (Org.). Uma introdução a Vygotsky. São Paulo: Loyola, 2002.

WERTSCH, J. V. La voz de la racionalidad em um enfoque sociocultural de la mente. In: MOLL, L. C. Vygotsky y la educación. Buenos Aires: Aique, 1993.

ZINCHENKO, V. P. A psicologia histórico-social e a teoria psicológica da atividade: retrospectos e prospectos. In: WERTSCH, James V.; DEL RÍO, P.; ALVAREZ, Amélia. (Orgs.). Estudos socioculturais da mente. Porto Alegre: Artmed, 1998.

Texto recebido em 13 mar. 2004 Texto aprovado em 22 set. 2004 